\title{
Cyclooxygenase-2 expression and its association with thyroid lesions
}

Kinga Krawczyk-Rusiecka ${ }^{1,2}$, Andrzej Lewiński1,2

1Department of Endocrinology and Metabolic Diseases, Medical University of Lodz, Lodz, Poland

2Polish Mother's Memorial Hospital - Research Institute, Lodz, Poland

Submitted: 20 May 2009

Accepted: 22 July 2009

Arch Med Sci 2010; 6, 5: 653-657

DOI: 10.5114/aoms.2010.17076

Copyright $\odot 2010$ Termedia \& Banach

\begin{abstract}
Cyclooxygenase (COX), also known as prostaglandin $\mathrm{H}$ synthase, catalyses the formation of prostaglandins from arachidonic acid. It can be expressed in response to various stimuli, such as hormones, mitogens, cytokines, other inflammatory mediators and growth factors. The product of COX-2 activity has been implicated in carcinogenesis by promoting angiogenesis, inhibiting apoptosis, increasing cell invasion and stimulating cell proliferation. It has also been proved that the regular intake of non-steroidal anti-inflammatory drugs (NSAIDs) decreases the risk of developing colon and breast cancers. Thus, it speaks for an important role of COX-2 in growth processes of various types of neoplasms. The connection between COX-2 activity and carcinogenesis has also been examined in human thyroid neoplasms. COX-2 overexpression has been reported in thyroid cancers and also in inflammatory conditions. In consequence there is significant interest whether COX-2 could be of importance as a molecular marker of malignancy in the case of thyroid carcinoma.
\end{abstract}

Key words: cyclooxygenase-2 gene, expression, thyroid lesions.

\section{Introduction}

Non-steroidal anti-inflammatory drugs (NSAIDs) inhibit the enzyme cyclooxygenase (COX), which is the key enzyme in biosynthesis of proinflammatory prostaglandins from arachidonic acid [1]. This notion has been supported by suppression of inflammatory responses in a number of clinical courses with experimental animals, followed by analysis of human cell cultures. It has been proved that regular intake of NSAIDs decreases the risk of developing colon cancer [2, 3]. Non-steroidal antiinflammatory drugs have also been of interest for researchers, as to whether their regular intake could possibly decrease the risk of developing other types of cancer.

\section{Cyclooxygenase enzymes}

The cyclooxygenases are a group of enzymes that catalyse the formation of prostaglandins from arachidonic acid. The COX-1 gene is located on chromosome $9 q$ and encodes a $66-k D a$ protein, whereas the COX-2 gene is found on chromosome 1 and encodes a $70-k D a$ protein, which has $61 \%$ homology with the product of COX-1 [4].

\author{
Corresponding author: \\ Andrzej Lewiński MD, PhD \\ Department of Endocrinology \\ and Metabolic Diseases \\ Medical University of Lodz \\ ul. Rzgowska 281/289 \\ 93-338 Lodz, Poland \\ Phone: + 48422711715 \\ Fax: +48 422711343 \\ E-mail: \\ alewin@csk.umed.lodz.pl
}


Cyclooxygenase-1 is a constitutive form, thought to be a housekeeping gene, with constant levels of expression in most tissues. It is indispensable in order to maintain physiological functions, such as gastric cytoprotection, vascular homeostasis and kidney function (mediated by prostaglandins); also it regulates normal platelet function, which is mediated by thromboxane [5]. As regards the thyroid gland, COX-1 has not been a subject of excessive interest, perhaps except for medullary thyroid carcinoma [6, 7]. On the other hand, COX-2 is expressed at baseline levels and is frequently undetectable in normal tissues. The relation of COX-2 to pathological phenomena in the thyroid gland seems to be much closer and is a subject of intensive research. Additionally, it should be mentioned that lipoxygenase (LOX), like COX-1, has not aroused more interest as regards the thyroid.

Besides NSAIDs, also corticosteroids decrease COX-2 expression or downregulate transcript isoforms of COX-2 $[8,9]$. It has recently been reported that aurothiomalate inhibits COX-2 expression in chondrocytes and in human cartilage, possibly through its effects on COX-2 mRNA stability [10]. Also, studies on certain plant extracts' effect on COX-2 expression in cancer cells are being conducted, but the subject requires further elucidation [11].

\section{Cyclooxygenase-2 and carcinogenesis}

It can be expressed in response to various stimuli, such as hormones, mitogens, cytokines, other inflammatory mediators and growth factors via protein kinase C and Ras-mediated signalling [12, 13]. The product of COX-2 activity has been implicated in carcinogenesis by promoting angiogenesis, inhibiting apoptosis, increasing cell invasion and stimulating cell proliferation [14-17]. It also modulates vascular endothelial growth factor (VEGF) synthesis; this action promotes angiogenesis and decreases immunity towards cancer cells $[18,19]$.

Recent studies have shown that up-regulation of COX-2 is associated with numerous neoplasms, including head and neck squamous cell, colorectal, breast, lung, skin, stomach, liver, pancreas, bladder, ovary and prostate cancers [20-35]. Epidemiological data suggest that the regular use of NSAIDs can significantly lower the risk of developing breast cancer, by approximately $50 \%$. A prospective study of over 600,000 adults has indicated that aspirin use decreases the risk of colon cancer by up to $50 \%$. A prospective cohort of 49,700 male health professionals has shown that a regular intake of aspirin lowers the risk of metastatic and fatal colon cancers, whereas "The Nurses' Health Study" has found a decreased risk of colorectal cancer among women taking two or more aspirin tablets per week, for 10 or more consecutive years [36, 37].
No epidemiological and/or randomized studies have - so far - been performed in humans to determine the protective properties of selective COX-2 inhibitors, but experimental animal data are fairly promising. COX-2 knockout mice develop about $75 \%$ fewer chemically induced skin papilloma [38]. In another study, null mutation for COX-2 in Apc $\Delta 716$ mice (a murine model of familial adenomatosis) caused a marked reduction of intestinal polyps and suppressed angiogenesis because of lowered expression of VEGF. Administration of COX-2 inhibitor caused further polyp reduction in that case $[39,40]$.

Some of the published studies suggest an important relationship between COX-2 activity and the severity of illness, especially in carcinomas of the gastrointestinal tract. It concerns mostly the depth of invasion, the size of the tumour and the amount of metastases into lymph nodes. In these cases, the main source of increased COX-2 protein product is not fibroblasts or proinflammatory cells but tumour cells themselves [13].

\section{Cyclooxygenase-2 and thyroid cancer}

Thyroid cancer is the most common endocrine malignancy and its most frequent types include well-differentiated thyroid cancers - papillary (PTC) and follicular (FTC) types, accounting for approximately $95 \%$ of all thyroid cancers.

The connection between COX-2 activity and carcinogenesis has also been examined in human thyroid neoplasms. The involvement of the COX pathway in the process of inflammation and in cellular growth in the thyroid has been considered. Interestingly, in the study of Larson et al. [41], patients with Hashimoto thyroiditis were three times more likely to have thyroid cancer, suggesting a strong link between chronic inflammation and cancer development.

There are also many well-known genetic alterations associated with thyroid cancer that could account for an increase in COX-2 expression. Ras oncogene mutations have been found with high frequency in benign and malignant thyroid tumours, in all stages of human thyroid tumourigenesis [42, 43]. Fibroblasts, transformed with a mutant Ha-Ras oncogene respond with a rapid induction of COX-2 [44]. Also, Ha-Ras expression in intestinal epithelial cells leads to expression of COX-2 [45].

Another genetic factor is the RET protooncogene. It has previously been shown to activate Ras, and thus it could indirectly lead to COX-2 activation. Whether RET could activate COX-2 in any other way is a matter of further investigation [46].

All but one of the conducted studies demonstrate overexpression of COX-2 in cases of PTC and FTC. In the immunohistochemical study of Ito et al. [47], there were 9 COX-2-negative cases out of 49 PTC 
(18.4\%). The authors also suggested a significant reduction of COX-2 levels in elderly patients (above 54 years old), in patients with large tumours and with advanced disease stages, as well as with the presence of solid, scirrhous or trabecular growth pattern.

However, in the study of Kajita et al. [48] and Garcia-Gonzales et al. [49] age was associated with an increased incidence of PTC. The results of Kajita et al. [48] did not show any significant differences in COX-2 expression between normal thyroid tissue and PTC, because of the observed variation in mRNA levels. The authors also performed an in vitro study with the TPC-1 thyroid carcinoma cell line and NS-398, a COX-2 enzymatic activity specific inhibitor, showing suppression of tumour cell growth. They confirmed the role of COX-2 in the growth of papillary thyroid cell lines [48].

Cornetta et al. [50] examined a variety of thyroid tissue specimens. COX-2 staining was not observed in specimens obtained from normal thyroid tissue, multinodular goitre, or anaplastic carcinoma. An analysis of Hashimoto's thyroiditis revealed COX-2 expression in follicular epithelium and lymphocytic infiltrates, as well as in cells of FTC and PTC [50].

The immunohistochemical study of Lee et al. [51] showed prominent expression of COX-2 in thyroiditis, and in benign and malignant thyroid lesions, but not in normal thyroid tissue. Nor did the authors observe any difference in the levels of COX-2 expression between different tumour tissue types. Because of the same intensity of COX-2 staining found in thyroiditis, and benign and malignant thyroid lesions, the authors concluded that COX-2 expression is unlikely to be related to the progression of thyroid disease.

Specht et al. [52] reported overexpression of COX-2 in 8 out of 10 cases of thyroid cancer, specific for tumour cells but not for surrounding stroma. They found that both COX-2 mRNA and protein increase in malignant thyroid nodules, when compared to benign nodules and adjacent normal thyroid tissue.

The results of experiments with Apc $\Delta 716$ knockout mice suggest that the induction of COX-2 is a very early event in colon carcinogenesis. That thesis has been supported by Garcia-Gonzales et al. [49], who suggest that even though COX-2 plays an important role in the progression of all thyroid cancers, in the case of PTC it seems to be more important only in the early stages of the cancer.

Rather limited data can be traced on the role of COX-2 in follicular neoplasms, due to the small number of patients enrolled into clinical studies. FTC is believed to arise from pre-existing follicular thyroid adenoma (FTA), indicating that FTA is a prominent candidate for a precursor of FTC, although this statement is still to be confirmed. In the largest published series of cases evaluating follicular neoplasms with COX-2, Nose et al. [53] assessed immunoreactivity in 41 FTC and 23 FTA; they observed strong COX-2 expression in all the cases. In the earlier cited paper by lto et al. [47], the authors performed immunohistochemical staining of COX-2 in 22 FTC and 15 FTA. Cyclooxygenase- 2 overexpression was found in $40.9 \%$ of FTC and $20 \%$ of FTA but without any statistical significance in COX-2 expression between those two clinical entities. Cyclooxygenase-2 overexpression was also found in the study of Haynik et al. [54]; that study included 34 patients with FTC and demonstrated increased COX-2 expression in $26 \%$ of them. There was no association between positive staining for COX-2 and other prognostic indicators (vascular invasion, capsular penetration, necrosis or Hürthle cell lesion) but the authors found a higher percentage of recurrences or metastases and of tumours that caused death in cases with COX-2positive staining [54].

On the other hand, the experimental study by Fuhrer et al. [55], using real time PCR, showed similar COX-2 mRNA expression levels in benign and malignant follicular neoplasms, normal thyroid tissue and Graves' disease samples. The authors concluded that COX-2 usefulness as a molecular marker for follicular thyroid neoplasia is markedly limited.

\section{Cyclooxygenase- 2 and thyroiditis}

Cyclooxygenase-2 overexpression has been reported not only in thyroid cancers but also in inflammatory conditions, such as thyroiditis. Chronic inflammation, leading to neoplastic transformation by promoting genomic instability, is a well established clinical phenomenon. The relation of thyroid neoplasm to Hashimoto disease has already been reported in a very early paper [56].

An association between Hashimoto thyroiditis and thyroid cancer remains controversial, with various authors reporting different frequencies, e.g., as high as 43.8\% [41] or 11-36\% [57]. Another study shows that transformed thyrocytes were able to induce COX-2 expression in follicular cells and to secrete IL- 6 in response to IL- $1 \beta$ and TNF- $\alpha$ [58]. Therefore, COX-2 expression in Hashimoto's thyroiditis may predispose the thyroid follicular epithelium to secrete proinflammatory cytokines, such as IL-6, potentiating an inflammatory response and the risk of developing thyroid carcinoma [50].

Enhanced expression of COX-2 in lymphocytic thyroiditis (Hashimoto's thyroiditis) suggests an important role of this enzyme in the inflammatory processes of the thyroid gland. There have been several studies supporting this thesis, based on immunohistochemical analysis, showing 
overexpression of COX-2 in inflammatory thyroid tissue [49-53]. However, in a recent study, Lo et al. [59], using immunohistochemical evaluation of examined specimens, did not detect COX-2 expression in lymphocytic thyroiditis.

In conclusions, the usefulness of COX-2 as a marker of thyroid malignancy has been challenged, but its potential role in carcinogenesis has aroused significant interest.

Fine needle aspiration biopsy has become a critical component in the management of thyroid nodules. It allows the number of cases requiring surgical treatment to be decreased from $67 \%$ to $44 \%$. Also the percentage of surgically treated carcinomas in those nodules increased from 14\% up to $29 \%$ [60]. Preoperative discrimination of thyroid malignancy, using not only cytopathology but also a molecular marker, would enhance proper diagnosis.

The frequent negativity of COX-2 staining in undifferentiated thyroid carcinomas and FTC indicates that COX-2 is not always useful as a marker of malignancy. When discussing this matter, we should consider the important finding that COX-2 expression was found to be significantly higher in PTC. Therefore, its application in diagnosing thyroid malignancy would be limited to PTC cases. Accordingly, COX-2 expression has been documented in a relatively large number of patients with PTC. Therefore, it could be useful in patients with diagnostic difficulties and suspicion of PTC.

Due to promising preclinical data, there are some clinical studies assessing the efficacy of selective COX-2 inhibitors in various malignancies, either alone or in combination with other treatment possibilities. Based on the above-mentioned studies, it would be important to establish whether selective COX-2 inhibitors could play some role in prevention of thyroid malignancies.

\section{References}

1. Radi ZA. Pathophysiology of cyclooxygenase inhibition in animal models. Toxicol Pathol 2009; 37: 34-46.

2. Thun MJ, Namboodiri MM, Heath CW Jr. Aspirin use and reduced risk of fatal colon cancer. N Engl J Med 1991; 325: 1593-6.

3. Kawamori T, Rao CV, Seibert K, Reddy BS. Chemopreventive activity of celecoxib, a specific cyclooxygenase2 inhibitor, against colon carcinogenesis. Cancer Res 1998; 58: 409-12.

4. Hla T, Neilson K. Human cyclooxygenase-2 cDNA. Proc Natl Acad Sci USA 1992; 89: 7384-8.

5. Herschmann HR. Prostaglandin synthase 2. Biochim Biophys Acta 1996; 1299: 125-40.

6. Bell CD, Vidal S, Kovacs K, Horvath E, Rotondo F. An immunohistochemical survey of nine cases of medullary carcinoma of thyroid including reactivity for Cox-1 and Cox-2 enzymes. Endocr Pathol 2002; 13: 331-40.

7. Quidville V, Segond N, Lausson S, Frenkian M, Cohen R, Jullienne A. 15-Hydroxyprostaglandin-dehydrogenase is involved in anti-proliferative effect of non-steroidal antiinflammatory drugs COX-1 inhibitors on a human medullary thyroid carcinoma cell line. Prostaglandins Other Lipid Mediat 2006; 81: 14-30.

8. Ristimäki A, Narko K, Hla T. Down-regulation of cytokineinduced cyclo-oxygenase-2 transcript isoforms by dexamethasone: evidence for post-transcriptional regulation. Biochem J 1996; 318: 325-31.

9. Lasa M, Brook M, Saklatvala J, Clark AR. Dexamethasone destabilizes cyclooxygenase 2 mRNA by inhibiting mitogen-activated protein kinase p38. Mol Cell Biol 2001; 21: 771-80.

10. Nieminen R, Vuolteenaho K, Riutta A, et al. Aurothiomalate inhibits COX-2 expression in chondrocytes and in human cartilage possibly through its effects on COX-2 mRNA stability. Eur J Pharmacol 2008; 587: 309-16.

11. Hung WC, Chang HC. Methanolic extract of adlay seed suppresses COX-2 expression of human lung cancer cells via inhibition of gene transcription. J Agric Food Chem 2003; 51: 7333-7.

12. Califano D, Rizzo C, D’Alessio A, et al. Signaling through Ras is essential for ret oncogene - induced cell differentiation in PC12 cells. J Biol Chem 2000; 275: 19297-305.

13. Jones DA, Carlton DP, Mclntyre TM, Zimmerman GA, Prescott SM. Molecular cloning of human prostaglandin endoperoxide synthase type II and demonstration of expression in response tocytokines. J Biol Chem 1993; 268: 9049-54.

14. Tsujii M, DuBois RN. Alterations in cellular adhesion and apoptosis in epithelial cells overexpressing prostaglandin endoperoxide synthase 2. Cell 1995; 83: 493-501.

15. Tsujii M, Kawano S, DuBois RN. Cyclooxygenase-2 expression in human colon cancer cells increases metastatic potential. Proc Natl Acad Sci USA 1997; 94 : 3336-40.

16. Sawaoka H, Tsuji S, Tsujii M, et al. Cyclooxygenase inhibitors suppress angiogenesis and reduce tumor growth in vivo. Lab Invest 1999; 79: 1469-77.

17. Fosslien E. Molecular pathology of cyclooxygenase-2cancer-induced angiogenesis. Ann Clin Lab Sci 2001; 31: 325-48.

18. Siironen P, Ristimäki A, Narko K, et al. VEGF-C and COX-2 expression in papillary thyroid cancer. Endocr Relat Cancer 2006; 13: 465-73.

19. Soh EY, Duh QY, Sobhi SA, et al. Vascular endothelial growth factor expression is higher in differentiated thyroid cancer than in normal or benign thyroid. J Clin Endocrinol Metab 1997; 82: 3741-7.

20. Chan G, Boyle JO, Yang EK, et al. Cyclooxygenase-2 expression is up-regulated in squamous cell carcinoma of the head and neck. Cancer Res 1999; 59: 991-4.

21. Hwang D, Scollard D, Byrne J, Levine E. Expression of cyclooxygenase-1 and cyclooxygenase- 2 in human breast cancer. J Natl Cancer Inst 1998; 90: 455-60.

22. Kulkarni S, Rader JS, Zhang F, et al. Cyclooxygenase-2 is overexpressed in human cervical cancer. Clin Cancer Res 2001; 7: 429-34.

23. van Rees BP, Saukkonen K, Ristimaki A, et al. Cyclooxygenase-2expression during carcinogenesis in the human stomach. J Pathol 2002; 196: 171-9.

24. Shirahama T, Sakakura C. Overexpression of cyclooxygenase- 2 in squamous cell carcinoma of the urinary bladder. Clin Cancer Res 2001; 7: 558-61.

25. Soslow RA, Dannenberg AJ, Rush D, et al. COX-2 is expressed in human pulmonary, colonic and mammary tumors. Cancer 2000; 89: 2637-45. 
26. Eberhart CE, Coffey RJ, Radhika A, Giardiello FM, Ferrenbach S, DuBois RN. Up-regulation of cyclooxygenase-2 gene expression in human colorectal adenomas and adenocarcinomas. Gastroenterology 1994; 107: 1183-8.

27. Zimmermann KC, Sarbia M, Weber AA, Borchard F, Gabbert HE, Schrör K. Cyclooxygenase-2 expression in human esophageal carcinoma. Cancer Res 1999; 59: 198-204.

28. Agoff SN, Brentnall TA, Crispin DA, et al. The role of cyclooxygenase-2 in ulcerative colitis-associated neoplasia. Am J Pathol 2000; 157: 737-45.

29. Koga H, Sakisaka S, Ohishi M, et al. Expression of cyclooxygenase-2 in human hepatocellular carcinoma: relevance to tumor dedifferentiation. Hepatology 1999 29: 688-96.

30. Hayashi N, Yamamoto H, Hiraoka N, et al. Differential expression of cyclooxygenase-2 (COX-2) in human bile duct epithelial cells and bile duct neoplasm. Hepatology 2001; 34; 638-50.

31. Wolf $H$, Saukkonen K, Anttila S, Karjalainen A, Vainio $H$, Ristimaki A. Expression of cyclooxygenase-2 in human lung carcinoma. Cancer Res 1998; 58: 4997-5001.

32. Sung JJ, Leung WK, Go MY, et al. Cyclooxygenase-2 expression in Helicobacter pylori-associated premalignant and malignant gastric lesions. Am J Pathol 2000; 157: 729-35.

33. Sano H, Kawahito $\mathrm{Y}$, Wilder RL, et al. Expression of cyclooxygenase-1 and -2 in human colorectal cancer. Cancer Res 1995; 55: 3785-9.

34. Okami J, Yamamoto H, Fujiwara Y, et al. Overexpression of cyclooxygenase-2 in carcinoma of the pancreas. Clin Cancer Res 1999; 5: 2018-24.

35. Wilson KT, Fu S, Ramanujam KS, Meltzer SJ. Increased expression of inducible nitric oxide synthase and cyclooxygenase- 2 in Barrett's and associated adenocarcinomas. Cancer Res 1998; 58: 2929-34.

36. Mazhar D, Gillmore R, Waxmann J. COX and cancer. Q J Med 2005; 98: 711-8.

37. Giovannucci E, Egan KM, Hunter DJ, et al. Aspirin and the risk of colorectal cancer in women. N Engl J Med 1995; 333: 609-14.

38. Tiano $H$, Chulada $P$, Spalding J, et al. Effects of cyclooxygenase deficiency on inflammation and papilloma development in mouse skin. Proc Am Assoc Cancer Res 1997; 38: 1727

39. Oshima M, Murai N, Kargman S, et al. Chemoprevention of intestinal polyposis in the Apc $\Delta 716$ mouse by rofecoxib, a specific cyclooxygenase-2 inhibitor. Cancer Res 2001; 61: $1733-40$

40. Oshima M, Dinchuk JE, Kargman SL, et al. Suppression of intestinal polyposis in Apc $\Delta 716$ knockout mice by inhibition of cyclooxygenase 2 (COX-2). Cell 1996; 87: 803-9.

41. Larson SD, Jackson LN, Riall TS, et al. Increased incidence of well differentiated thyroid cancer associated with Hashimoto thyroiditis and the role of PI3k/Akt Pathway. J Am Coll Surg 2007; 204: 764-75.

42. Lemoine NR, Mayall ES, Wyllie FS, et al. High frequency of ras oncogene activation in all stages of human thyroid tumorigenesis. Oncogene 1989; 4: 159-64.

43. Namba H, Rubin SA, Fagin JA. Point mutations of ras oncogenes are an early event in thyroid tumorigenesis. Mol Endocrinol 1990; 4: 1474-9.

44. Sheng H, Willimas CS, Shao J, Liang P, DuBois RN, Beauchamp RD. Induction of cyclooxygenase-2 by activated Ha-ras oncogene in Rat-1 fibroblasts and the role of mitogen-activated protein kinase pathway. J Biol Chem 1998; 273: 22120-7.

45. Sheng H, Shao J, Dixon DA, et al. TGF-1 enhances Ha-Rasinduced expression of cyclooxygenase- 2 in intestinal epithelial cells via stabilization of mRNA. J Biol Chem 2000; 275: 6628-35.

46. Lam KY, Montone KT, Nolan Ka, LiVolsi VA. Ret oncogene activation in papillary thyroid carcinoma: prevalence and implication of the histological implications. Human Pathol 1998; 29: 565-8.

47. Ito Y, Yoshida H, Nakano K, et al. Cyclooxygenase-2 expression in thyroid neoplasms. Histopathology 2003; 42: 492-7.

48. Kajita S, Ruebel KH, Casey MB, Nakamura N, Lloyd RV. Role of COX-2, thromboxane A2 synthase, and prostaglandin 12 synthase in papillary thyroid carcinoma growth. Mod Pathol 2005; 18: 221-7.

49. Garcia-Gonzales M, Abdulkader I, Vazquez Boquete A, Neo X M, Forteza J, Cameselle-Teijeiro J. Cyclooxygenase-2 in normal, hyperplastic and neoplastic follicular cells of the human thyroid gland. Virch Arch 2005; 447: 12-7.

50. Cornetta AJ, Russell JP, Cunnane M, Keane WM, Rothstein JL. Cyclooxygenase-2 expression in human thyroid carcinoma and Hashimoto's thyroiditis. Laryngoscope 2002; 112: 238-42

51. Lee KJ, Jung YS, Kim WH, Yoon TI, Joo HJ, Soh EY. Cyclooxygenase-2 expression in human thyroid disease. J Endocrinol Invest 2008; 31: 111-8.

52. Specht MC, Tucker ON, Hocever M, Gonzalez D, Teng L, Fahey TJ III. Cyclooxygenase-2 expression in thyroid nodules. J Clin Endocrinol Metab 2002; 87: 358-63.

53. Nose F, Ichikawa T, Fujiwara M, Okayasu I. Up-regulation of cyclooxygenase-2 expression in lymphocytic thyroiditis and thyroid tumors. Am J Clin Pathol 2002; 117: 546-51.

54. Haynik DM, Prayson RA. Immunohistochemical expression of cyclooxygenase 2 in follicular carcinomas of the thyroid. Arch Pathol Lab Med 2005; 129: 736-41.

55. Fuhrer D, Eszlinger M, Karger S, et al. Evaluation of insulinlike growth factor II, cyclooxygenase-2, ets-1 and thyroidspecific thyroglobulin mRNA expression in benign and malignant thyroid tumours. Eur J Endocrinol 2005; 152: 785-90.

56. Dailey ME, Lindsay S, Skahen R. Relation of thyroid neoplasm to Hashimoto disease of the thyroid gland. AMA Arch Surg 1955; 70: 291-7.

57. Repplinger D, Barger A, Zhang Yi-Wei, Adler JT, Haymart $M$, Chen $H$. Is Hashimoto's thyroiditis a risk factor for papillary thyroid cancer? J Surg Res 2008; 150: 49-52.

58. Berg J, Stöcher M, Bogner S, Wölfl S, Pichler R, Stekel H. Inducible cyclooxygenase-2 gene expression in the human thyroid epithelial cell line Nthy-ori3-1. Inflamm Res 2000; 49: 139-43.

59. Lo CY, Lam KY, Leung PP, Luk JM. High prevalence of cylooxygenase 2 expression in papillary thyroid carcinoma. Eur J Endocrinol 2005; 152: 545-50.

60. Hamberger B, Gharib H, Melton LJ, Goellner JR, Zinsmeister AR. Fine-needle aspiration biopsy of thyroid nodules. Impact on thyroid practice and cost of care. Am J Med 1982; 73: 381-4. 